\title{
Falhas da reprodução na pecuária bovina de corte com ênfase para causas infecciosas ${ }^{1}$
}

\section{Reproductive failures in beef cattle breeding herds with emphasis for infectious causes}

\author{
José R. C. Junqueira ${ }^{2}$; Amauri A. Alfieri ${ }^{3^{*}}$
}

Resumo

\begin{abstract}
Na pecuária bovina de corte especializada na cria de bezerros a eficiência da reprodução é um dos aspectos de maior destaque para o sucesso financeiro do investimento. Na presente revisão serão abordados os principais parâmetros utilizados para avaliar o desempenho reprodutivo de vacas de corte criadas extensivamente, bem como as principais causas infecciosas de falhas na reprodução que comprometem os custos da produção.
\end{abstract}

Palavras-chave: Bovinos, reprodução, IBR, BVD, leptospirose

\begin{abstract}
The reproductive efficiency in beef cattle breeding herds is one of the aspects of greater highlight for the financial success of the investment. In the present revision the main parameters used to evaluate the reproductive performance of cows in extensive management will be approached, as well as the more important infectious causes of the reproductive failures that affect the costs of the production.
\end{abstract}

Key words: Cattle, reproduction, IBR, BVD, leptospirosis

1 Parte da Dissertação apresentada ao Programa de Pós-graduação em Ciência Animal, Centro de Ciências Agrárias (CCA), Universidade Estadual de Londrina (UEL), Londrina, PR.

2 Universidade do Oeste Paulista (UNOESTE), Presidente Prudente, SP.

3 Laboratório de Virologia Animal, Departamento de Medicina Veterinária Preventiva, CCA/UEL, Campus Universitário, caixa postal 6001, 86051-990 - Londrina, PR. E-mail: alfieri@uel.br

* Autor para correspondência. 


\section{Introdução}

A pecuária bovina brasileira passa por um processo de tecnificação da atividade, porém ainda co-existem duas situações bem distintas. Grande parte do rebanho nacional faz uso de alguma tecnologia de produção como melhoramento e/ou rotação de pastagem, alimentação intensiva, cruzamento industrial, seleção genética, manejo zootécnico-sanitário, inseminação artificial (IA), transferência de embriões (TE) e fertilização in vitro (FIV), que têm por objetivo o aumento dos índices zootécnicos e reprodutivos do rebanho (RODRIGUES; RODRIGUES, 2000). Em contrapartida, há ainda rebanhos em que a alimentação é realizada em pastos nativos, sem suplementação, com pouco ou nenhum controle sanitário e praticamente sem qualquer controle reprodutivo (SILVA, 2000). A somatória dessas duas situações faz com que os parâmetros reprodutivos e a taxa de desfrute do rebanho bovino nacional ainda não sejam os mais adequados, particularmente face aos custos atuais de produção.

De acordo com dados de 2004, o rebanho bovino brasileiro era composto por cerca de 170,2 milhões de cabeças, das quais aproximadamente 135,4 milhões são de gado de corte e 34,8 milhões de gado leiteiro. Dentre os bovinos de corte, aproximadamente 17,8 milhões são provenientes de cruzamento industrial. Do total do rebanho bovino brasileiro, aproximadamente 75,7 milhões de animais estão em idade de reprodução (ANUALPEC, 2005). A inseminação artificial (IA) é realizada em apenas, aproximadamente, $4 \%$ do total das fêmeas aptas à reprodução, sendo que a maior proporção ocorre em animais com aptidão leiteira e em bovinos de corte de elite. Situação totalmente distinta é observada em outros países como os Estados Unidos da América, Dinamarca e Israel onde, respectivamente, 70\%, 95\% e 100\% das fêmeas são inseminadas (SILVA, 2000).

\section{Parâmetros da Reprodução}

Em rebanhos de reprodução de bovinos de corte, para o retorno financeiro do investimento, algumas taxas de eficiência reprodutiva devem ser alcançadas. O número médio de doses de sêmen, ou de serviços, por concepção deve ser de 1,3 a 1,6 o que representa o percentual médio de $60 \%$ a $70 \%$ de concepção ao primeiro serviço. O intervalo de partos de 13 a 14 meses é considerado aceitável, porém, o ideal é de 12 meses. Intervalo superior a 14 meses pode refletir deficiências reprodutivas no rebanho. Considerando o total de vacas aptas para a reprodução, a taxa de natalidade aceitável deve ser de $85 \%$. O período de serviço ideal para bovinos de corte é de 85 dias e taxas de bezerros desmamados acima de $78 \%$ são consideradas adequadas (VELLOSO, 1999).

A idade ideal para o primeiro parto de uma novilha de corte é próxima aos dois anos e uma vaca deve produzir um bezerro saudável a cada ano. Para alcançar altos índices de prolificidade e de produtividade, os rebanhos de bovinos de corte devem atingir taxas mínimas de $92 \%$ a $96 \%$ de concepção, $85 \%$ a $90 \%$ de nascimento, e máximas de $1 \%$ a $2 \%$ de abortamento e de $5 \%$ de mortalidade pós-natal.

Os parâmetros comentados anteriormente são utilizados com maior freqüência para a avaliação da fertilidade de rebanhos bovinos de corte. Porém, outros como a percentagem de fêmeas adultas prenhes ao primeiro serviço, a faixa etária da fêmea à puberdade e ao primeiro parto e o número de bezerros nascidos por vaca durante toda a sua vida produtiva também podem ser utilizados (VELLOSO, 1999). O quadro 3 apresenta os percentuais mínimos e os desejáveis para cinco parâmetros de eficiência reprodutiva de rebanhos de bovinos de corte em regime extensivo de criação. 
Quadro 1. Denominação das fases do concepto conforme o período de gestação da fêmea bovina.

\begin{tabular}{cc}
\hline Fases & Período Pós-Concepção \\
\hline Ovo ou Zigoto & Até o $12^{\circ}$ dia \\
Embrião & $13^{\circ}$ ao $46^{\circ}$ dia \\
Feto & $\geq 46^{\circ}$ dia \\
\hline
\end{tabular}

Adaptado de: Gomes (1978).

Quadro 2. Distribuição dos tipos de falhas na reprodução de bovinos, de acordo com o período de ocorrência.

\begin{tabular}{cc}
\hline Falhas & Período \\
\hline Mortalidade Embrionária Precoce & Concepção $-14^{\circ}$ dia/gestação \\
Mortalidade Embrionária Tardia & $15^{\circ}-46^{\circ}$ dia/gestação \\
Aborto & $47^{\circ}-270^{\circ}$ dia/gestação \\
Mortalidade Perinatal & i) $270^{\circ}$ dia/gestação a termo; \\
Mortalidade Neonatal & ii) até $24 \mathrm{~h}$ após o nascimento \\
Mortalidade Tardia & $1^{\circ}$ ao $28^{\circ}$ dia de idade \\
\hline
\end{tabular}

Adaptado de: Radostits, Leslie e Fetrow (1996)

Tabela 1. Taxas de cinco parâmetros de eficiência reprodutiva para rebanhos de bovinos de corte em regime extensivo de criação.

\begin{tabular}{ccc}
\hline \multirow{2}{*}{ Parâmetros } & \multicolumn{2}{c}{ Eficiência Reprodutiva } \\
\cline { 2 - 3 } & Alta (\%) & Mínima (\%) \\
\hline Concepção & $92-96$ & 85 \\
Natalidade & $85-90$ & 83 \\
Desmame & 85 & 78 \\
Aborto & $1-2$ & $1-2$ \\
Mortalidade pré-desmame & $\leq 5$ & $\geq 5$ \\
\hline
\end{tabular}

Adaptado de: Radostits, Leslie e Fetrow (1996) e Velloso (1999).

\section{Falhas da Reprodução}

Os problemas reprodutivos caracterizados como anestro, falha de concepção, infertilidade e mortalidades embrionária e/ou fetal, são responsáveis por uma gama de sinais clínicos como ausência ou repetição de cio, tanto a intervalo regular quanto irregular, abortamento, natimortalidade, mortalidades perinatal e/ou neonatal. O nascimento de animal debilitado e a retenção de placenta são duas outras formas comuns de manifestação clínica de distúrbios da reprodução. Como conseqüências podem ser observadas alterações significativas nos parâmetros da reprodução tais como o aumento do intervalo de partos, aumento do número de doses de sêmen ou de serviços por concepção e redução no número de animais nascidos e desmamados. Essas alterações acarretam reduções nas taxas de fertilidade do rebanho ocasionando prejuízos econômicos significativos à exploração bovina. As fases de desenvolvimento do concepto e o período gestacional de ocorrência das principais falhas da reprodução, para a espécie bovina, são apresentadas nos quadros 1 e 2 , respectivamente.

Na pecuária bovina de corte, especializada na cria de bezerros, o manejo reprodutivo destaca-se como um dos principais aspectos responsáveis pelo desempenho econômico da atividade. Vários fatores podem interferir nas taxas de reprodução. Dentre eles, os mais significativos são aqueles relacionados à genética, à nutrição e ao manejo zootécnico dos 
rebanhos. Esses fatores, por serem mais facilmente visualizados e inclusive quantificados, nas criações mais tecnificadas são sempre os primeiros a serem corrigidos nas situações onde os parâmetros reprodutivos estão abaixo do esperado para esse tipo de exploração pecuária.

Porém, a sanidade do rebanho, em particular relacionada às infecções que direta ou indiretamente comprometem o trato reprodutivo das fêmeas e dos machos e o embrião e/ou feto, também se destaca como um importante fator de interferência na eficiência reprodutiva dos rebanhos bovinos de corte.

As doenças da reprodução podem ocorrer de forma epidêmica ou endêmica. Nos rebanhos livres, a introdução do agente etiológico acarretará, na maioria das vezes, em que a infecção se manifeste de forma epidêmica. Nessa situação, podem ser comprometidos simultaneamente muitos animais de diferentes categorias, que podem expressar sinais clínicos variados como repetição de cio, abortamento, natimortalidade, nascimento de animal fraco e infertilidade. Devido à ocorrência quase que simultânea desses distúrbios da reprodução em uma percentagem expressiva de animais do rebanho, e por ocasionar prejuízos econômicos significativos num curto período de tempo, tanto o diagnóstico quanto o controle da forma epidêmica são realizados mais precocemente.

Em rebanhos anteriormente infectados, devido à natureza biológica dos principais agentes etiológicos que apresentam tendência à cronicidade, a forma endêmica prevalece. Nessa situação, os distúrbios reprodutivos podem ainda persistir no rebanho, porém em número e intensidade inferiores à forma epidêmica. Na dependência do agente etiológico, falhas na reprodução podem ocorrer novamente em animais já infectados, entretanto os animais ainda não portadores e aqueles recém incorporados ao rebanho, como as novilhas de reposição e vacas primíparas, são os que freqüentemente apresentam os menores índices reprodutivos. Entretanto, como na forma endêmica as falhas na reprodução são mais esporádicas e comprometem menor número de animais, os prejuízos econômicos devidos a esse tipo de infecção são mais difíceis de serem mensuráveis. Com isso, tanto o diagnóstico quanto a adoção de condutas de controle e profilaxia não são realizados de forma rotineira e, no médio e/ou longo prazos, o prejuízo econômico pode também tornar-se significativo.

\section{Etiologia}

Os distúrbios da reprodução em bovinos são multifatoriais e multietiológicos. Várias etiologias de origem infecciosa e não-infecciosa, atuando de forma isolada ou em associação, podem influir tanto diretamente quanto indiretamente nos parâmetros utilizados para a avaliação da eficiência reprodutiva de rebanhos bovinos de corte criados extensivamente.

As causas não-infecciosas, em conjunto, são as principais responsáveis por perdas reprodutivas na pecuária bovina de corte, destacando-se entre elas as falhas nutricionais envolvendo a carência e/ou o excesso de macro e microelementos (minerais e vitaminas) e aquelas relacionadas ao manejo da reprodução (MAYNARDI et al., 1984; LOTTHAMMER, 1988; YAGER et al., 1998; RESENDE, 2001). Porém, a presente revisão dará ênfase às causas infecciosas que ocasionam problemas da reprodução em bovinos de corte, criados extensivamente.

Os problemas sanitários de ordem infecciosa que determinam falhas na reprodução de bovinos são multietiológicos e podem ser classificados como causas primárias ou secundárias.

As causas secundárias caracterizam-se por serem esporádicas e podem ocorrer após qualquer infecção sistêmica que determine manifestação clínica geral e hipertermia, seguida de morte do embrião ou feto. A tristeza parasitária bovina e a mastite clínica, causada por microrganismos gramnegativos, entre outros, são dois exemplos clássicos dessa categoria de problemas reprodutivos em 
bovinos. Nessas situações a anamnese bem conduzida, indicando a presença de sinais clínicos sistêmicos, de ocorrência imediatamente anterior ou concomitantemente ao abortamento, pode ser o suficiente para a realização do diagnóstico clínico do problema reprodutivo.

As causas primárias de problemas reprodutivos podem ocorrer de forma epidêmica ou endêmica. A introdução de um microrganismo em um rebanho livre determina que os problemas reprodutivos ocorram de forma epidêmica, com vários animais apresentando diferentes sinais clínicos reprodutivos simultaneamente. Em rebanhos já infectados as causas primárias apresentam tendência a manifestarem-se de forma endêmica onde poucos animais, particularmente aqueles que ainda não foram infectados ou soronegativos, ou apenas algumas categorias de animais manifestam sinais clínicos reprodutivos.

Vários microrganismos como vírus, bactérias, protozoários e mesmo toxinas produzidas por fungos podem, isoladamente ou em associação, ocasionar distúrbios da reprodução em bovinos (VANROOSE; KRUIF; VAN SOOM, 2000). Alguns microrganismos podem ser considerados patógenos primários do trato reprodutivo e outros secundários. No caso dos patógenos primários os sinais clínicos são restritos à esfera reprodutiva. Os patógenos secundários ocasionam infecção localizada ou sistêmica com conseqüências reprodutivas (JESUS, 2001). O quadro 4 apresenta os principais microrganismos que podem infectar a fêmea bovina e determinar distúrbios reprodutivos.

Quadro 3. Principais microrganismos causadores de problemas reprodutivos em bovinos

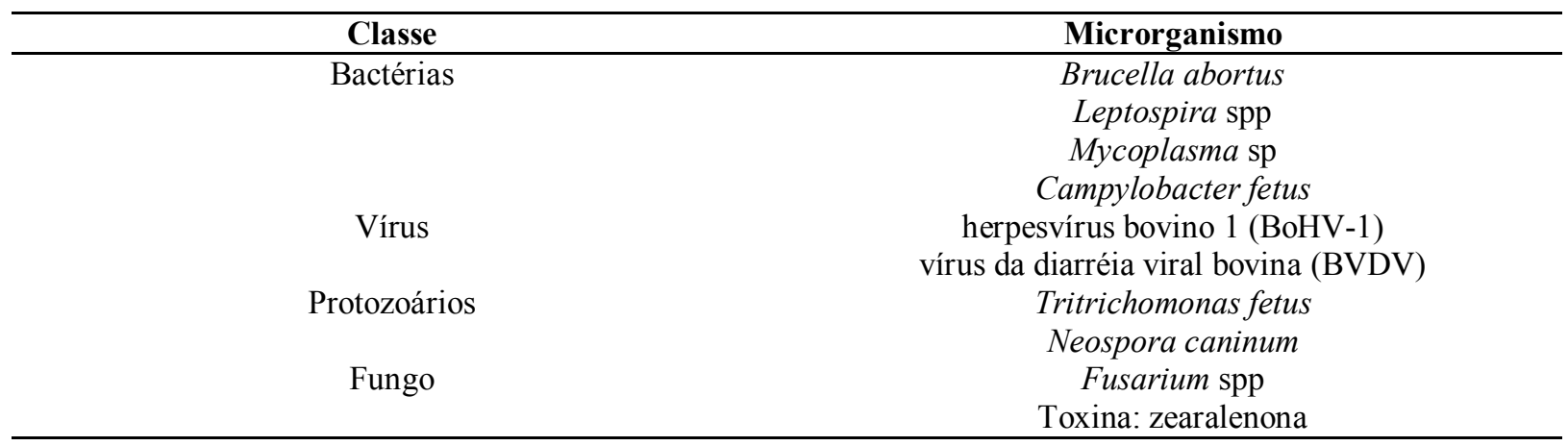

Dentre as doenças infecto-contagiosas que determinam distúrbios reprodutivos em bovinos destacam-se: i) a campilobacteriose, a tricomonose e a micoplasmose que são transmitidas exclusivamente por contato venéreo; ii) a brucelose, a leptospirose, a neosporose, a rinotraqueíte infecciosa bovina (IBR) e a diarréia viral bovina (BVD) têm a via oronasal como a principal via de contaminação, podendo também, em algumas situações, serem transmitidas por contato venéreo (HIRTH; NIELSEN; POURTELLOTTE, 1970;
JESUS, 2001). Outros microrganismos como Haemophilus somnus, Chlamydia sp, bactérias gram-positivas e/ou gram-negativas e fungos também podem ser relacionados, esporadicamente, a falhas da reprodução em bovinos. Porém, a freqüência de problemas reprodutivos determinados por esses microrganismos é baixa tanto pela não realização de diagnóstico etiológico quanto pela ocorrência. $\mathrm{O}$ quadro 5 apresenta os principais sinais clínicos ocasionados por alguns patógenos primários e secundários do aparelho reprodutivo da fêmea bovina. 
Junqueira, J. R.; Alfieri, A. A.

Quadro 4. Sinais clínicos ocasionados pelos principais patógenos do aparelho reprodutivo de bovinos.

\begin{tabular}{|c|c|c|c|c|c|c|c|}
\hline Microrganismo & RCR & RCI & $\mathbf{A B}$ & NM & MN & NAF & $\mathbf{R P}$ \\
\hline Brucella abortus & & & $\mathrm{X}$ & & & & $\mathrm{X}$ \\
\hline Leptospira spp & & $\mathrm{X}$ & $\mathrm{X}$ & $\mathrm{X}$ & & $\mathrm{X}$ & $\mathrm{X}$ \\
\hline Mycoplasma $\mathrm{sp}$ & & $\mathrm{X}$ & $\mathrm{X}$ & & & $\mathrm{X}$ & \\
\hline Campylobacter fetus & & $\mathrm{X}$ & $\mathrm{X}$ & & & & \\
\hline BoHV-1 & $\mathrm{X}$ & $\mathrm{X}$ & $\mathrm{X}$ & $\mathrm{X}$ & $\mathrm{X}$ & $\mathrm{X}$ & \\
\hline BVDV & & $\mathrm{X}$ & $\mathrm{X}$ & $\mathrm{X}$ & & $\mathrm{X}$ & \\
\hline Neospora caninum & & & $\mathrm{X}$ & & & $\mathrm{X}$ & \\
\hline Tritrichomonas fetus & & $\mathrm{X}$ & $\mathrm{X}$ & & & $\mathrm{X}$ & \\
\hline Fungo (Toxina: Zearalenona) & & $\mathrm{X}$ & $\mathrm{X}$ & & & & \\
\hline
\end{tabular}

RCR (Repetição de cio regular); RCI (Repetição de cio irregular); AB (Abortamento);

NM (Natimortalidade); MN (Mortalidade Neonatal); NAF (Nascimento Animal Fraco);

RP (Retenção de Placenta); BoHV-1 (herpesvírus bovino 1); BVDV (vírus da diarréia viral bovina).

\section{IBR, BVD e Leptospirose}

A IBR, a BVD e a leptospirose são importantes doenças infecciosas de bovinos que, além dos sinais clínicos sistêmicos, podem também ocasionar redução na eficiência reprodutiva e, em conseqüência, determinar prejuízos econômicos significativos à exploração pecuária.

Em rebanhos bovinos soronegativos para o BoHV1, BVDV e Leptospira spp, a infecção por esses microrganismos, tanto de forma isolada quanto principalmente em associação, ocasiona conseqüências diretas na esfera reprodutiva onde podem ser observados, simultaneamente, diferentes sinais clínicos. Na dependência do estádio gestacional essas infecções podem determinar mortalidades embrionárias, fetais ou neonatais, que se refletem como repetição de cio a intervalos regulares/ irregulares, abortamentos, natimortalidades e o nascimento de animais debilitados, com peso corporal abaixo da média da raça (ELLIS et al., 1982; McGOWAN; KIRKLAND, 1995; RUDAN et al., 1999; TAKIUCHI et al., 2005).

Resultados de levantamentos sorológicos realizados em várias regiões geográficas do Brasil demonstram que uma grande proporção de animais do plantel de reprodução dos rebanhos bovinos brasileiros, tanto de corte quanto de leite, é soropositiva para um, dois ou mesmo para os três agentes etiológicos simultaneamente. Essa soropositividade indica que em algum momento os animais se infectaram com esses microrganismos (LILENBAUM, 1996; ROCHA; GOUVEIA; LEITE, 1998; LEITE, 1999; RICHTZENHAIN et al., 1999; MÉDICI; ALFIERI; ALFIERI, 2000; TAKIUCHI; ALFIERI; ALFIERI, 2001).

$\mathrm{Na}$ epidemiologia da IBR, BVD e leptospirose devem ser consideradas as diferentes estratégias biológicas dos agentes etiológicos dessas doenças infecciosas para a sua manutenção e mesmo perpetuação no rebanho, com a conseqüente infecção dos animais soronegativos. A estratégia de latência viral do BoHV-1 faz do animal infectado um portador assintomático e potencial transmissor do vírus devido aos freqüentes episódios de reexcreção viral (ACKERMANN; PETERHANS; WYLER, 1982). $\mathrm{Na}$ infecção pelo BVDV uma pequena proporção (1\% a $2 \%$ ) dos animais nascidos pode ser constituída por animais persistentemente infectados (PI) e a presença de animais PI é a principal forma de transmissão e manutenção do vírus no rebanho (NETTLETON; ENTRICAN, 1995). A Leptospira spp tem a habilidade de instalar-se em estruturas renais, ficando dessa forma inacessível aos anticorpos, podendo ser eliminada pela urina por até dois anos ou mais, sendo o animal portador a principal fonte de infecção para os susceptíveis (GERRITSEN et al., 1994).

As diferentes estratégias empregadas por esses microrganismos para a manutenção da infecção no rebanho fazem com que, tanto o BoHV-1 quanto o 
BVDV e a Leptospira spp, possam perpetuar-se nos rebanhos, desde que não sejam tomadas medidas adequadas de controle e profilaxia. Nessa situação, os problemas reprodutivos determinados por essas infecções tornam-se endêmicos, sendo expressos, em particular, naqueles animais ainda não infectados. Com isso, diferentemente da forma de apresentação epidêmica, que prevalece quando o patógeno não está presente no rebanho, na forma endêmica a avaliação das conseqüências da infecção na esfera reprodutiva deve ser criteriosa, uma vez que apenas uma parcela do rebanho, constituída pelos animais soronegativos, deverá manifestar de maneira mais significativa os distúrbios reprodutivos induzidos por esses microrganismos.

Os sinais clínicos relacionados à esfera reprodutiva e ocasionados pela IBR, BVD e leptospirose, com raras exceções, são muito semelhantes. Essa característica inviabiliza a realização do diagnóstico clínico conclusivo. $\mathrm{O}$ diagnóstico laboratorial, quando realizado por meio de técnicas sorológicas, possibilita o prévio conhecimento do perfil epidemiológico do rebanho com relação a determinadas etiologias. Porém, apenas em raras situações a sorologia pode ser utilizada como ferramenta de diagnóstico definitivo. Destacam-se nesse contexto as flutuações de títulos observadas em animais soropositivos pertencentes às diferentes categorias do rebanho, a presença de animais com altos títulos de anticorpos específicos e também aquelas situações onde é possível realizar a sorologia pareada. A prática de vacinação pode também prejudicar, ou mesmo inviabilizar, a realização do diagnóstico sorológico. Com isso, na maioria das infecções do aparelho reprodutivo o diagnóstico etiológico conclusivo somente pode ser realizado por meio de técnicas laboratoriais que possibilitem a identificação do agente etiológico ou de seus componentes como proteínas e ácido nucléico (TAKIUCHI et al., 2003; CLAUS et al., 2005; FERREIRA et al., 2005; PILZ; ALFIERI; ALFIERI, 2005).

\section{Custos da Produção}

Independentemente da causa ou da origem do distúrbio reprodutivo, se infeccioso ou não, o resultado final será sempre o menor número de nascimentos e o maior intervalo entre partos. Essas duas conseqüências acarretarão redução na receita e aumento dos custos da atividade.

Em um passado recente as margens de lucro da pecuária bovina brasileira e a valorização da terra permitiam rentabilidade ao produtor, mesmo em rebanhos com taxas reduzidas de fertilidade. Atualmente, com a redução na margem de lucro da atividade de cria da pecuária de corte, se torna cada vez mais imprescindível o incremento nos índices reprodutivos do rebanho.

Os custos da atividade pecuária podem ser distribuídos em custos fixos e custos variáveis. Nos custos fixos estão incluídos: mão de obra, encargos sociais, depreciações, administração, consultorias, impostos/taxas, entre outros menos expressivos. Nos custos variáveis incluem-se: insumos pecuários (sal mineralizado, vermífugos, vacinas), combustíveis, calcário/fertilizantes, manutenção de pastagens, cercas, veículos, tratores e implementos, entre outros (ANUALPEC, 2005).

Uma unidade animal (1 UA) corresponde a um animal de $450 \mathrm{~kg}$ de peso vivo, que equivale ao peso de uma vaca em regime extensivo de criação, e tem o custo médio anual de US\$77.97. Nesse valor estão incluídos os custos fixos, que correspondem a 35$40 \%$ e os custos variáveis responsáveis por $65-70 \%$ do valor total da UA. (ANUALPEC, 2005).

O ciclo de produção na pecuária bovina de corte é anual e, portanto, todas as informações econômicas relevantes devem ser calculadas em bases anuais, pois tanto a receita quanto alguns custos são sazonais. Com base nos custos, uma vaca que não produz um bezerro por ano, em conseqüência de mortalidade embrionária precoce ou tardia, abortamento, mortalidade perinatal, e mortalidade neonatal, gera uma despesa sem retorno de US\$77.97. 
Existem basicamente duas formas de aumento da rentabilidade em um sistema de produção na pecuária bovina de corte. A primeira é reduzir os custos de produção, o que nem sempre é possível sem comprometer a atividade. A segunda é aumentar, de forma racional, as taxas de fertilidade do rebanho. Isso pode ser obtido com a melhoria genética e de pastagens, a implantação de cruzamento industrial e de biotécnicas da reprodução, tais como IA, TE e FIV, e também por meio do incremento da saúde do rebanho, particularmente com relação aos patógenos que comprometem a reprodução.

\section{Perfil Sanitário}

Com relação aos problemas sanitários que interferem nas taxas que são utilizadas como parâmetros na avaliação da eficiência reprodutiva, a primeira providência a ser tomada é a realização do perfil sanitário do rebanho. Para isso, a avaliação sorológica assume grande importância, inicialmente na determinação da existência ou não do problema e, em um segundo momento, na quantificação do problema no rebanho. A determinação da freqüência de ocorrência de algumas doenças infecciosas que determinam reflexos negativos na eficiência reprodutiva possibilitará a avaliação do percentual de animais infectados e de susceptíveis.

Para aquelas infecções que são incompatíveis com um sistema de produção, como a brucelose, a determinação do percentual de animais soropositivos, bem como sua identificação, é de extrema importância uma vez que o descarte é a medida preconizada. Para outras doenças como a leptospirose, a sorologia é útil para caracterizar a presença da infecção no rebanho, e com isto possibilitar a adoção de medidas de tratamento e/ou de controle e profilaxia em todo o rebanho. Para aquelas infecções onde ainda é possível a manutenção do animal infectado no rebanho, a exemplo da IBR e da BVD, a sorologia além de indicar a presença da infecção possibilita ainda a determinação daquelas categorias de animais susceptíveis, onde o percentual de animais soronegativos é maior. Com isso, medidas de controle e profilaxia, e em especial de imunoprofilaxia, podem ser adotadas em todo o rebanho ou, de forma estratégica, naquelas categorias de animais susceptíveis, destacando-se as novilhas e/ou as vacas primíparas. Em etapas mais avançadas de um programa sanitário a identificação e a eliminação de animais persistentemente infectados pelo BVDV também é uma estratégia que deve ser considerada, assim como a realização de diagnóstico etiológico para a IBR e para a BVD.

Para algumas infecções com característica venérea como a campilobacteriose, a tricomonose e a micoplasmose genital apenas a realização do diagnóstico sorológico não fornecerá muitas informações. Vacas com campilobacteriose e tricomonose poderão se recuperar da infecção (MEDEIROS; FIGUEIREDO, 1971; STOESSEL, 1982). Entretanto, os touros tornam-se portadores assintomáticos perpetuando os patógenos no rebanho (SKIRROW; DURANT, 1988; EAGLESOME; GARCIA, 1992). Com isso, esses animais podem tanto reinfectar as vacas quanto ser fonte primária de infecção para aqueles animais que ainda não tiveram contato com o patógeno, como as novilhas (CLARK; DUFTY; PARSONSON, 1977; DEKEYSER, 1984). Nessas situações, o recomendável é o diagnóstico etiológico, com a identificação do microrganismo ou de seus componentes como proteínas ou ácido nucléico.

Em ambas as situações, o diagnóstico sorológico e o etiológico são ferramentas indispensáveis para a adoção de condutas de controle e profilaxia de doenças infecciosas que interferem na reprodução de bovinos, bem como para a avaliação da eficiência das medidas preconizadas.

Em conclusão, a adoção de manejo zootécnicosanitário eficiente, particularmente no que diz respeito ao monitoramento da eficiência reprodutiva do rebanho, é de fundamental importância para que a rentabilidade da produção de bovinos de corte seja positiva. 


\section{Agradecimentos}

Os recursos financeiros utilizados para a realização desse trabalho foram obtidos nas seguintes agências de fomento à pesquisa: CNPq, CAPES e Fundação Araucária (FAP/PR). Alfieri, A.A. é bolsista produtividade do CNPq.

\section{Referências}

ACKERMANN, M.; PETERHANS, E.; WYLER, R. DNA of bovine herpesvirus type 1 in the trigeminal ganglia of latently infected calves. American Journal of Veterinary Research, Schaumburg, v.43, n.1, p.36-40, 1982.

ANUALPEC 2005: anuário da pecuária brasileira. São Paulo: Instituto FNP - Ed. FNP Consultoria \& Comércio, 2005.

CLARK, B. L.; DUFTY, J. H.; PARSONSON, I. M. Studies on the transmission of Tritrichomonas foetus. Australian Veterinary Journal, Melbourne, v.53, p.170-173, 1977.

CLAUS, M. P.; ALFIERI, A. F.; FOLGUERASFLATSCHART, A. V.; WOSIACKI, S. R.; MÉDICI, K. C.; ALFIERI, A. A.. Rapid detection and differentiation of bovine herpesvirus 1 and 5 glycoprotein $\mathrm{C}$ in clinical specimens by multiplex-PCR. Journal of Virological Methods, Amsterdam, v.128, p.183-188, 2005.

DEKEYSER, J. Bovine Genital Campylobacteriosis. In: BUTZLER, J. P. Campylobacter infection in man and animals. Boca Raton: CRC Press, 1984. p.181-191.

EAGLESOME, M. D.; GARCIA, M. M. Microbial agents associated with bovine genital tract infection and semen. Part I. Brucella abortus, Leptospira interrogans, Campylobacter fetus, Tritrichomonas foetus. Veterinary Bulletin, London, v.62, p.743-775, 1992.

ELLIS, W. A.; O'BRIEN, J. J.; NEILL, S. D.; HANNA, J. Bovine leptospirosis: Serological findings in aborting cows. Veterinary Record, London, v.110, p.178-180, 1982.

FERREIRA, M. C.; MÉDICI, K. C.; ALFIERI, A. F.; ALFIERI, A. A. Desenvolvimento e avaliação de um ensaio imunoenzimático para o diagnóstico sorológico da infecção pelo herpesvírus bovino 1. Semina: Ciências Agrárias, Londrina, v.26, n.3, prelo, 2005.

GERRITSEN, M. J.; KOOPMANS, M. J.; DEKKER, T. C. E. M.; DEJONG, M. C. M.; MOERMAN, A.; OLYHOEK, T. Effective treatment with dihydroestreptomycin of naturally infected cow shedding Leptospira interrogans serovar hardjo subtype hardjobovis. American Journal of Veterinary Research, Schaumburg, v.55, n.3, p.18-23, 1994.
GOMES, W. R. Gestación. In: SALISBURY, G. W.; VANDEMARK, N. L.; LODGE, J. R. Fisiologia de la Reproduccion e Inseminacion Artificial de los Bovidos. 2 ed. Zaragoza: Acribia, 1978.

HIRTH, R. S.; NIELSEN, S. W.; POURTELLOTTE, M. E. Characterization and comparative genital tract pathogenicity of bovine mycoplasmas. Infection and Immunity, Washington, v.2, p.101-104, 1970.

JESUS, V. I. T. Fatores de risco das doenças infecciosas. Revista Brasileira de Reprodução Animal, Belo Horizonte, v.25, n.2, p.93-96, 2001.

LEITE, R. C. Controle da diarréia bovina a vírus (DBV) e rinotraqueíte infecciosa bovina (IBR). Revista Brasileira de Reprodução Animal, Belo Horizonte, v.23, n.4, p.531535, 1999.

LILENBAUM, W. Atualização em leptospiroses bovinas. Revista Brasileira de Medicina Veterinária, Rio de Janeiro, v.18, n.1, p.9-13, 1996.

LOTTHAMMER, K. H. Transtornos de la fertilidad de origen ambiental. In: GRUNERT, E.; BERCHTOLD, M. Infertilidad en la vaca. Buenos Aires: Hemisferio Sur, 1988. p.375-385.

MAYNARDI, L. A.; LOOSLI, J. K.; HINTZ, H. F.; WARNER, R. G. Nutrição animal. 3 ed. Rio de Janeiro: Freitas Bastos, 1984.

McGOWAN, M. R; KIRKLAND, P. D. Early reproductive loss due to bovine pestivirus infection. British Veterinary Journal, London, v.151, p.263-270, 1995.

MEDEIROS, P. M.; FIGUEIREDO, J. B. Trichomonose bovina em Minas Gerais: comunicação. Arquivos da Escola de Veterinária da UFMG, Belo Horizonte, v.23, p.143-147, 1971.

MÉDICI, K. C.; ALFIERI, A. A.; ALFIERI, A. F. Prevalência de anticorpos neutralizantes contra o herpesvírus bovino tipo 1, decorrente de infecção natural, em rebanhos com distúrbios reprodutivos. Ciência Rural, Santa Maria, v.30, n.2, p.347-350, 2000.

NETTLETON, P. F.; ENTRICAN, G. Ruminant pestiviruses. British Veterinary Journal, London, v.151, p.615-642, 1995.

PILZ, D.; ALFIERI, A. F.; ALFIERI, A. A. Comparação de diferentes protocolos para a detecção do vírus da diarréia viral bovina por RT-PCR em grupos de sangue total e de soro sangüíneo, artificialmente contaminados. Semina Ciências Agrárias, Londrina, v.26, n.2, p.211-220, 2005.

RADOSTITS, O. M.; LESLIE, K. E.; FETROW, J. Planned animal health and production in beef cattle breeding herds. Herd Health Food Animal Production Medicine. 2 ed. Philadelphia: W.B. Saunders Company, 1996. p.331-393 
RESENDE, O. A. Problemas não-infecciosos que afetam a reprodução de bovinos: visão do veterinário de campo. Revista Brasileira de Reprodução Animal, Belo Horizonte, v.25, n.2, p.96-101, 2001.

RICHTZENHAIN, L. J.; ALFIERI, A. A.; LEITE, R. C.; WEIBLEN, R.; MORO, E.; UMEHARA, O. Pesquisa de anticorpos séricos contra o herpesvírus bovino tipo $1 \mathrm{em}$ fêmeas de propriedades com histórico de problemas reprodutivos, localizadas em 21 estados brasileiros. Arquivo do Instituto Biológico, São Paulo, v.66, supl.1, p.127, 1999.

ROCHA, M. A.; GOUVEIA, A. M. G.; LEITE, R. C. O vírus da IBR e a inseminação artificial em bovinos. Revista Brasileira de Reprodução Animal, Belo Horizonte, v.22, n.2, p.70-73, 1998.

RODRIGUES, B. A.; RODRIGUES, J. L. Histórico, avanços e aspectos éticos das biotécnicas de reprodução. Revista Brasileira de Reprodução Animal, Belo Horizonte, v.24, n.1,p.10-17, 2000.

RUDAN, N. B; CVETNIC, S; MADIC, J; RUDAN, D. Prevalence of antibodies to IBR and BVD viruses in dairy cows with reproductive disorders. Theriogenology, New York, v.51, n.5, p.875-881, 1999.

SILVA, N. Biotecnologia aplicada à reprodução animal: perspectivas presentes e futuras. Revista Brasileira de Reprodução Animal, Belo Horizonte, v.24, n.1, p.17-20, 2000.

SKIRROW, S. Z.; DURANT, B. Bovine Trichomoniasis. Veterinary Bulletin, London, v.58, n.8, p.591-603, 1988.
STOESSEL, F. Las enfermidades venereas de los bovinos: trichomoniasis y vibriosis genital. Zaragoza: Acribia, 1982.

TAKIUCHI, E.; ALFIERI, A.F.; ALFIERI, A. A. Herpesvírus bovino tipo 1: Tópicos sobre a infecção e métodos de diagnóstico. Semina: Ciências Agrárias, Londrina, v.22, n.2, p.203-209, 2001.

TAKIUCHI, E.; MÉDICI, K.C.; ALFIERI, A. F.; ALFIERI, A. A. Otimização da reação em cadeia pela polimerase (semi-nested PCR) para a detecção do herpesvírus bovino tipo 1 em fragmentos de órgãos fetais e em sêmen de bovinos naturalmente infectados. Semina: Ciências Agrárias, Londrina, v.24, p.43-56, 2003.

Bovine herpesvirus type 1 abortions detected by a semi nested-PCR in Brazilian cattle herds. Research in Veterinary Science, London, v.79, n.1, p.85-88, 2005.

VANROOSE, G.; KRUIF, A.; VAN SOOM, A. Embryonic mortality and embryo-pathogen interactions. Animal Reproduction Science, Amsterdam, v.60-61, p.131-143, 2000.

VELLOSO, L. Manejo da reprodução em bovinocultura de corte. In: . Bovinocultura de corte: fundamentos da exploração racional. 3.ed. Piracicaba: FEALQ, 1999. p. $43-60$

YAEGER, M. J.; NEIGER, R. D.; HOLLER, L.; FRASER, T. L.; HURLEY, D. J.; PALMER, I. S. The effect of subclinical selenium toxicosis on pregnant beef cattle. Journal of Veterinary Diagnostic Investigation, Turlock, v.10, p.268273,1998 . 